Gut, 1974, 15, 521-525

\title{
Faecal fat excretion after truncal, selective, and highly selective vagotomy for duodenal ulcer
}

\author{
J. P. EDWARDS, P. J. LYNDON, R. B. SMITH, AND D. JOHNSTON \\ From the University Department of Surgery, The General Infirmary, Leeds
}

SUMMARY Faecal fat excretion was measured on a metabolic ward in 16 patients with duodenal ulcer before operation, and in patients who were in good health more than one year after truncal vagotomy and pyloroplasty $(n=11)$, bilateral selective vagotomy and pyloroplasty $(n=9)$, or highly selective vagotomy without a drainage procedure (HSV, $n=12)$. Excretion of faecal fat was significantly greater $(P<0.01)$ in patients after both truncal and selective vagotomy with drainage than in patients before operation. Fat excretion in HSV patients was little different from that of preoperative patients.

If steatorrhoea is defined as a faecal fat output of more than $6 \mathrm{~g}$ per day, one of 16 preoperative patients with duodenal ulcer $(6 \%)$ had steatorrhoea, one of $12 \mathrm{HSV}$ patients $(8 \%)$ had steatorrhoea, one of nine patients after selective vagotomy and pyloroplasty (11\%) had steatorrhoea but five of 11 patients after truncal vagotomy and pyloroplasty (45\%) had steatorrhoea.

'Two hundred and fifty-five patients were investigated more than fifteen years after vagotomy and gastroenterostomy. Weight loss of more than $6 \mathrm{~kg}$ was observed in $32.5 \%$ of men and $60 \%$ of women. Haemoglobin levels below $90 \%$ were found in $43.5 \%$ of men, and below $80 \%$ in $84 \%$ of women; this anaemia was iron-deficient................ ............Pulmonary tuberculosis was found in $7 \%$ of patients' (Wheldon, Venables, and Johnston, 1970).

Both truncal and selective vagotomy with a drainage procedure $(T V+D, S V+D)$ lead to significant increases in faecal fat excretion in man (Fox and Grimson, 1950; Cox, Bond, Podmore, and Rose, 1964; Logan, 1964; Baldwin, Albo, Jaffe, and Silen, 1965; Butler and Eastham, 1965; Williams and Irvine, 1966; Wastell and Ellis, 1966), with the result that approximately $40 \%$ of patients have steatorrhoea (more than $6 \mathrm{~g}$ of fat per day in the stool). Much of the increase in faecal fat excretion may be due to the drainage procedure rather than to the vagotomy (Wastell and Ellis, 1966). The significance of this increased loss of faecal fat is not clear. Indeed, it is often assumed to have no clinical significance. However, since the amount of fat in the faeces is an index of the efficiency of the absorptive process, the finding of steatorrhoea in $40 \%$ of patients after Received for publication 21 March 1974. vagotomy with drainage suggests that losses of minerals and vitamins may also be excessive. In the long run, such malabsorption might contribute to the weight loss and anaemia which have been found in a high proportion of patients after vagotomy with a drainage procedure (Dellipiani, Macleod, Thompson, and Shivas, 1969; Wheldon et al, 1970).

For the past five years in the University Department of Surgery at Leeds General Infirmary patients with duodenal ulcer have been treated by highly selective vagotomy without a drainage procedure (HSV). In this operation, the hepatic and coeliac vagal fibres which supply the liver and biliary tract, pancreas, and small intestine are kept intact, as in selective vagotomy, but in addition the gastric antrum remains innervated and the pylorus is left intact. Thus both 'milling' of food in the stomach and control of gastric emptying should be better after HSV than after complete gastric vagotomy with a drainage procedure (Carlson, Code, and Nelson, 1966; Dozois, Kelly, and Code, 1971; Wilbur and Kelly, 1973). In consequence, losses of fat and of other nutriments in the faeces might be less. To test this hypothesis, we measured the output of faecal fat in patients with duodenal ulcer before operation, and in patients who had undergone truncal, bilateral selective, or highly selective vagotomy for duodenal ulcer more than one year previously. 


\section{Patients and Methods}

\section{PATIENTS}

Forty-eight patients were studied in the Metabolic Investigation Ward at Leeds General Infirmary. Sixteen had duodenal ulcer which was radiographically proven; 11 had undergone TV $+\mathrm{P}$; nine bilateral SV $+\mathrm{P}$, and 12 highly selective vagotomy. All the vagotomized patients had been operated upon for duodenal ulcer at least 12 months previously and were in good health at the time of testing. Details of their age, sex, weight, and clinical status are shown in the table.

\section{WARD PROCEDURE}

Patients were admitted to hospital for a period of eight or nine days. On admission each patient was interviewed by a dietician and a diet was devised which would conform with the individual patient's dietary habits, but at the same time contain $100 \mathrm{~g}$ of fat per day. In addition, each patient received $500 \mathrm{mg}$ of polyethylene glycol 4000 (PEG) three times a day with meals as a marker. During the period of investigation, patients were encouraged to take regular exercise in the form of walking, particularly after meals. The first three days were regarded as a period of equilibration (for diet and marker) and stool samples were discarded. The stools were then collected for the ensuing five days.

\section{CHEMICAL METHODS}

Faecal fat was estimated by Frazer's modification (Varley, 1967) of the method of van de Kamer, ten Bokkel Huinink, and Weyers (1949). This method yielded a coefficient of variation of $1.3 \%$ for $26 \mathrm{du}-$ plicate determinations. Polyethylene glycol was estimated by a modification (Davies, 1972) of the method of Hydén (1956). The coefficient of variation was $1.7 \%$.

\section{STATISTICAL METHODS}

The significance of differences in faecal fat excretion between groups was assessed by means of Mann and Whitney's (1947) modification of Wilcoxon's sum of ranks test (1945) for non-parametric data.

\section{Results}

The faecal fat outputs of the 48 individual patients are shown in figure 1 . The sex of the patient had no significant influence on faecal fat output in postoperative patients. Mean outputs of faecal fat and ranges in the four groups of patients were (in $\mathrm{g} /$ day): DU, 3.1 (1.6 to 6.3); HSV, 3.6 (2.2 to 8.7); SV + P, 4.9 (3.6 to 6.6); TV + P, 6.4 (3.3 to 13.7$)$.

There was no significant difference in faecal fat excretion between patients after HSV and patients with DU before operation. Also, fat excretion in patients after $\mathbf{S V}+\mathbf{P}$ did not differ significantly

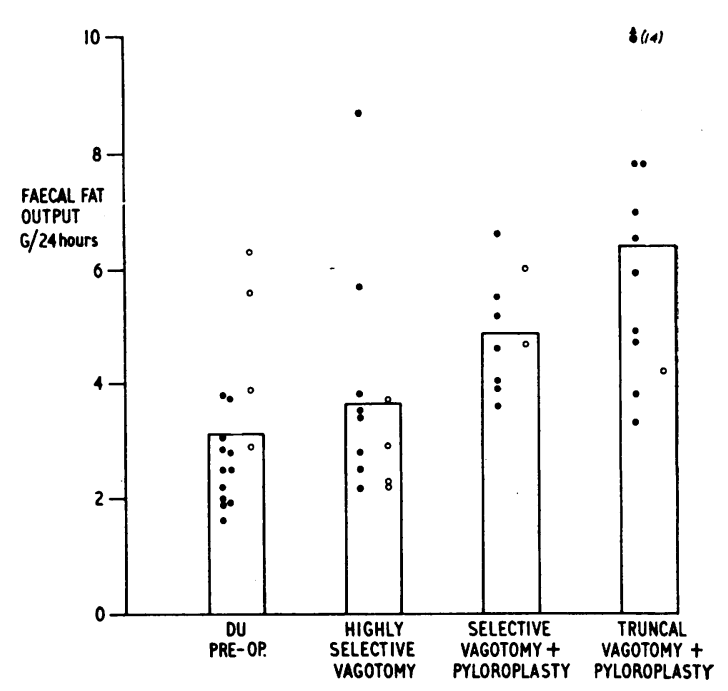

Fig 1 Closed circles represent males and open circles females. Horizontal lines represent the arithmetic means. The significance of differences between groups was calculated by methods applicable to non-parametric data (text). Faecal fat outputs are significantly greater in the truncal $V+P$ group and in the selective $V+P$ group than in the pre-operative $D U$ patients. Also, fat outputs after both $T V+P$ and $S V+P$ are greater than after $H S V$. The difference between the HSV and preoperative $D U$ groups is not significant.

\begin{tabular}{|c|c|c|c|c|}
\hline Patients & $\begin{array}{l}\text { Preoperative } \\
\text { Duodenal Ulcer }\end{array}$ & $\begin{array}{l}\text { Truncal Vagotomy and } \\
\text { Pyloroplasty }\end{array}$ & $\begin{array}{l}\text { Selective Vagot omy and } \\
\text { Pyloroplasty }\end{array}$ & $\begin{array}{c}\text { Highly Selective } \\
\text { Vagotomy }(H S V)\end{array}$ \\
\hline 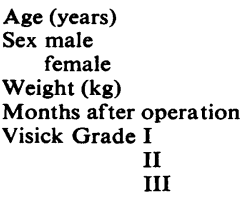 & $\begin{array}{l}39 \pm 3 \cdot 1 \\
12 \\
4 \\
62 \pm 3 \cdot 3 \\
-\end{array}$ & $\begin{array}{l}54 \pm 4 \cdot 4 \\
10 \\
1 \\
64 \pm 2 \cdot 4 \\
44 \pm 3 \cdot 8 \\
5 \\
3 \\
3\end{array}$ & $\begin{aligned} & 59 \pm 3 \cdot 2 \\
& 7 \\
& 2 \\
& 59 \pm 3 \cdot 4 \\
& 67 \pm 3 \cdot 4 \\
& 3 \\
& 3 \\
& 3\end{aligned}$ & $\begin{aligned} & 52 \pm 3 \cdot 9 \\
& 8 \\
& 4 \\
& 66 \pm 2 \cdot 9 \\
& 30 \pm 3 \cdot 1 \\
& 6 \\
& 4 \\
& 2\end{aligned}$ \\
\hline
\end{tabular}

Table Comparison of the four groups of subjects ${ }^{1}$

${ }^{1}$ Figures are arithmetic means plus or minus 1 standard error. 
from that of patients after TV $+P$. Faecal fat output in patients after $\mathbf{T V}+\mathbf{P}$ was significantly greater than in preoperative DU patients $(P<0.002)$ or than in patients after HSV $(P<0.01)$. Similarly, patients after $\mathbf{S V}+\mathbf{P}$ excreted significantly more fat than DU patients $(P<0.01)$ or patients after HSV (P < 0.01).

When male patients only were considered, again no significant difference was found between preoperative DU patients and patients after HSV. Also, there was no significant difference between the TV $+\mathbf{P}$ and the SV + P groups. Faecal fat output in men after TV $+\mathbf{P}$ was significantly greater than that of male DU patients before operation $(P<0.002)$, and also greater than that of men after HSV ( $P<$ 0.05). Similarly, men after SV + P excreted significantly more faecal fat than men before operation $(P<0.002)$, but the difference between the SV $+P$ and HSV groups was not significant, presumably because of the small numbers involved.

If, instead of the absolute data, only steatorrhoea (defined as a faecal fat output of more than $6 \mathrm{~g}$ per day) is considered, the results appear in a somewhat different light, because then no difference is found between the SV + P group and the HSV group of patients. Only one of 16 preoperative DU patients $(6 \%)$ had steatorrhoea, one of $12 \mathrm{HSV}$ patients $(8 \%)$ had steatorrhoea, one of nine patients after SV $+\mathbf{P}$ $(11 \%)$ had steatorrhoea, whereas no fewer than five

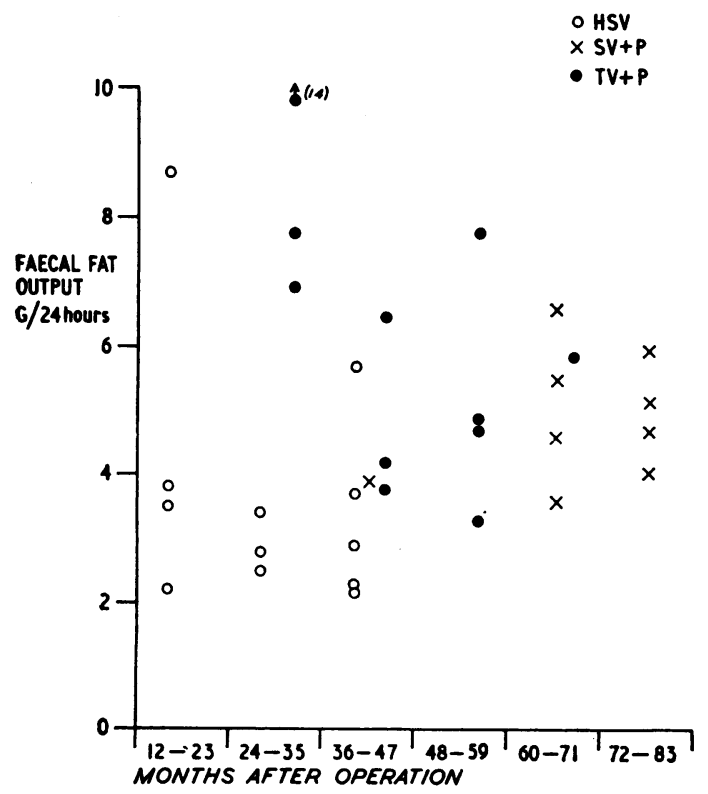

Fig 2 No evidence was found that the interval of time after operation had a significant influence on faecal fat output after vagotomy. of 11 patients after TV $+\mathbf{P}(45 \%)$ had steatorrhoea.

The mean interval between operation and the measurement of faecal fat excretion was $\mathbf{3 0}$ months in patients after HSV, 44 months in patients after TV $+P$, and 67 months in patients after SV $+P$ (see table). There was no evidence, however, that within each group faecal fat excretion either increased or decreased with increasing time after operation (fig 2).

\section{Discussion}

By admitting patients for eight days to a metabolic ward which is staffed by specially trained nurses, by controlling the intake of fat (Wollaeger, Comfort, and Osterberg, 1947; Walker, Kelleher, Davies, Smith, and Losowsky, 1973), and by using a nonabsorbable marker (Wilkinson, 1971), we attempted to exclude the major sources of error in the measurement of faecal fat excretion. In addition, the patients who were studied after vagotomy had achieved good clinical results, and had no significant upset of bowel function. None of them experienced diarrhoea in the course of the study.

Patients were found to excrete significantly more fat after truncal or selective vagotomy with pyloroplasty $(\mathrm{TV}+\mathrm{P}, \mathrm{SV}+\mathrm{P})$ than did patients with duodenal ulcer before operation. These findings are in accord with the results of previous studies (Fox and Grimson, 1950; Logan, 1964; Cox, Bond, Podmore, and Rose, 1964; Baldwin, Albo, Jaffe, and Siku, 1965; Butler and Eastham, 1965; Kraft, Kirsh, Kittleson, Ernst, Pollard, and Ransom, 1965; Wastell and Ellis, 1966; Williams and Irvine, 1966; Payne, Wighton, and Bluhm, 1970). Matching of the four groups of patients was not perfect in all respects (see table). The three groups of patients after vagotomy were well matched for age, body weight, and clinical status (Visick grade). There was a higher proportion of male patients in the TV + P group, but no evidence was found that faecal fat outputs were higher in males than in females (fig 1). Again, the mean interval after operation in the HSV group (30 months) was shorter than in the TV + P group (44 months) or SV + P group (67 months), but there was no evidence that faecal fat output correlated with the length of time after operation (fig 2).

In the course of normal digestion of a meal, solids are 'milled' in the antrum of the stomach and chyme is subsequently discharged in a regulated fashion through the pylorus into the duodenum, where it is mixed with pancreatic secretion and bile under the correct conditions for hydrolysis by pancreatic enzymes. Any surgical procedure which interferes with these processes might be expected to produce defects of absorption. Both truncal and bilateral selective vagotomy denervate the entire stomach 
and produce gastric stasis (Shiina and Griffith, 1969; Clarke, McFarland, and Williams, 1972). Hence the addition of a drainage procedure is necessary. Vagotomy combined with a drainage procedure leads to loss of control of gastric emptying and may result in the precipitate entry of inadequately homogenized food into the small intestine (Carlson, Code, and Nelson, 1966; McKelvey, 1970; Dozois, Kelly, and Code, 1971; Colmer, Owen, and Shields, 1973; Clarke and Alexander-Williams, 1973; Wilbur and Kelly, 1973; Wilkinson and Johnston, 1973). 'Dumping' is a relatively common side effect after both TV + P and SV + P (Goligher et al, 1968; Dellipiani et al, 1969; McKelvey, 1970; Goligher et al, 1972; Humphrey and Wilkinson, 1972;Humphrey, Johnston, Walker, Pulvertaft, and Goligher, 1972; Amdrup and Jensen, 1973; Colmer, Owen, and Shields, 1973). Rapid gastric emptying may be followed by rapid intestinal transit (McKelvey, 1970; Wilkinson and Johnston, 1973), and these factors, combined with poor mixing of unsuitable material with pancreatic secretion and bile, could provide an explanation for at least part of the increase in fat excretion which is found in patients after vagotomy with a drainage procedure. The use of a pyloroplasty seems to offer little advantage over gastroenterostomy in terms of reducing faecal fat excretion (Logan, 1964; Payne, Wighton, and Bluhm, 1970).

Since truncal vagotomy denervates the pancreas, biliary tract, duodenum, and small intestine, it might be expected to produce a major defect in fat absorption. Sarles, Dani, Prezelin, Souville, and Figarella (1968) and Novis, Bank, and Marks (1971) have shown that there is a cephalic phase of pancreatic secretion in man. Truncal vagotomy has been shown to impair the pancreatic exocrine response to insulin hypoglycaemia in man (Dreiling, Druckerman, and Hollander, 1952; Pfeffer, Stephenson, and Hinton, 1952; McKelvey, Toner, Connell, and Kennedy, 1973; Smith, Edwards, and Johnston, 1973). In addition, in patients after truncal vagotomy with a drainage procedure, Fields and Duthie (1965) found diminished amounts of lipase and of bile acids in the intestinal lumen after a test meal. Despite these findings, there is as yet little evidence that vagal denervation of the pancreas and biliary tract in man impairs digestion and absorption to a degree that is clinically important. Our own results show that faecal fat excretion is not significantly higher after truncal vagotomy and pyloroplasty than after selective vagotomy and pyloroplasty, which is in agreement with the previous findings of Wastell and Ellis (1966) and of Williams and Irvine (1966). Thus, preservation of the extragastric vagal fibres is not of crucial importance for the digestion of fat. However, in the present study, only one of nine patients (11\%) who had undergone SV + P excreted more than $6 \mathrm{~g}$ of fat per day, whereas five of the 11 patients $(45 \%)$ who had undergone TV + P excreted more than $6 \mathrm{~g}$ of fat per day. Thus our study provided some evidence of greater loss of faecal fat after truncal vagotomy than after selective vagotomy.

Faecal fat excretion was found to be significantly lower after HSV than after either TV + P or SV + P. In common with $S V+P$, HSV preserves the hepatic and coeliac vagal fibres but HSV preserves the antral 'mill' and the pylorus, whereas $\mathbf{S V}+\mathbf{P}$ destroys them. This suggests that the main reasons for the increased loss of faecal fat after both TV and SV with a drainage procedure are, first, impairment of the milling function of the antrum and, secondly, unregulated gastric emptying through the pyloroplasty or gastroenterostomy.

It has been shown previously that dumping and diarrhoea are significantly less common after HSV than after complete gastric vagotomy with a drainage procedure (Humphrey et al, 1972; Johnston, Humphrey, Walker, Pulvertaft, and Goligher, 1972; De Miguel, 1972). The results of this study show that faecal fat excretion is also significantly lower after HSV than after complete gastric vagotomy with a drainage procedure. Since the amount of fat in the faeces is a non-specific index of malabsorption, these results suggest that day-to-day losses of protein, minerals, and vitamins in the faeces may be less after HSV than after vagotomy with drainage. The metabolic defects which Wheldon and her colleagues (1970) demonstrated in patients 15 to 20 years after truncal vagotomy with gastroenterostomy are no doubt of diverse origin, but impaired absorption may well play an important part. Thus it will be interesting to see whether nutrition is better in the long term after HSV than after vagotomy with a drainage procedure.

We wish to express our gratitude to Sister V. Walker and the nursing staff of the Metabolic Ward, Leeds General Infirmary, for the care which they lavished on this project. We are indebted to Mrs J. Barg, the dietician, for her assistance and advice, to the patients themselves for volunteering to help, and to Mrs E. Nutter for the manuscript. We thank Professor J. C. Goligher for his support. R. B. Smith was supported by the Endowment Fund of Leeds General Infirmary, which also defrayed the expenses of the project.

\section{Roferences}

Amdrup, E., and Jensen, H. E. (1973). One hundred patients five years after selective gastric vagotomy and drainage for duodenal ulcer. Surgery, 74, 321-325.

Baldwin, J. N., Albo, R., Jaffe, B., and Silen, W. (1965). Metabolic effects of selective and total vagotomy. Surg. Gynec. Obstet. 120, $777-783$.

Butler, T. J., and Eastham, R. D. (1965). Absorption studies after 
gastrojejunostomy with and without vagotomy. Gut, 6, 69-72.

Carlson, H. C., Code, C. F., and Nelson, R. A. (1966). Motor action of the canine gastroduodenal junction: a cineradiographic, pressure and electric study. Amer. J. dig. Dis., 11, 155-172.

Clarke, R. J., McFarland, J. B., and Williams, J. A. (1972). Gastric stasis and gastric ulcer after selective vagotomy without a drainage procedure. Brit. med. J., 1, 538-539.

Clarke, R. J., and Williams, J. A. (1973). The effect of preserving antral innervation and of a pyloroplasty on gastric emptying after vagotomy in man. Gut, 14, 300-307.

Colmer, M. R., Owen, G. M., and Shields, R. (1973). Pattern of gastric emptying after vagotomy and pyloroplasty. Brit. med.J., 2, 448-450.

Cox, A. G., Bond, M. R., Podmore, D. A., and Rose, D. P. (1964). Aspects of nutrition after vagotomy and gastrojejunostomy. Brit. med. J., 1, 465-469.

Davies, T. (1972). Personal commmunication.

Dellipiani, A. W., Macleod, I. B., Thomson, J. W. W., and Shivas, A. A. (1969). Gastroenterostomy and vagotomy for chronic duodenal ulcer. Gut, 10, 366-374.

De Miguel, J. (1972). Diarrea tras diversas formas de vagotomia con y sin drenaje complementario. Rev. esp. Enferm. Apar. dig., 38, 595-600.

Dozois, R. R., Kelly, K. A., and Code, C. F. (1971). Effect of distal antrectomy on gastric emptying of liquids and solids. Gastroenterology, 61, 675-681.

Dreiling, D. A., Druckerman, L. J., and Hollander, F. (1952). The effect of complete vagisection and vagal stimulation on pancreatic secretion in man. Gastroenterology, 20, 578-586.

Fields, M., and Duthie, H. L. (1965). Effect of vagotomy on intraluminal digestion of fat in man. Gut, 6, 301-310.

Fox, H. J., and Grimson, K. S. (1950). Defective fat absorption following vagotomy. J. Lab. clin. Med., 35, 362-365.

Goligher, J. C., Pulvertaft, C. N., de Dombal, F. T., Conyers, J. H., Duthie, H. L., Feather, D. B., Latchmore, A. J. C., Shoesmith, J. H., Smiddy, F. G., and Willson-Pepper, J. (1968). Five- to eight-year results of Leeds/York controlled trial of elective surgery for duodenal ulcer. Brit. med. J., 2, 781-787.

Goligher, J. C., Pulvertaft, C. N., Irvin, T. T., Johnston, D., Walker, B., Hall, R. A., Willson-Pepper, J., and Matheson, T. S. (1972). Five- to eight-year results of truncal vagotomy and pyloroplasty for duodenal ulcer. Brit. med. J., 1, 7-13.

Humphrey, C. S., Johnston, D., Walker, B. E., Pulvertaft, C. N., and Goligher, J. C. (1972). Incidence of dumping after truncal and selective vagotomy with pyloroplasty and highly selective vagotomy without drainage procedure. Brit. med. J., 3, 785-788.

Humphrey, C. S., and Wilkinson, A. R. (1972). The value of preserving the pylorus in the surgery of duodenal ulcer. Brit.J. Surg., 59, 779-783.

Hydén, S. (1956). A turbidometric method for the determination of higher polyethylene glycols in biological materials. $K$. LantbrHögsk. Annlr., 22, 139-145.

Johnston, D., Humphrey, C. S., Walker, B. E., Pulvertaft, C. N., and Goligher, J. C. (1972). Vagotomy without diarrhoea. Brit. med. J., 3, 788-790.

Kamer, J. H. van de, ten Bokkel Huinink, H., and Weyers, H. A. (1949). Rapid method for the determination of fat in feces. $J$. biol. Chem., 177, 347-355.

Kraft, R. O., Kirsh, M. M., Kittleson, A. C., Ernst, C. B., Pollard,
H. M., and Ransom, H. K. (1965). Metabolic studies in patients subsequent to selective gastric vagotomy. Surg. Gynec. Obstet., 120, 472-474.

Logan, H. (1964). Steatorrhoea and diarrhoea after vagotomy: a comparison of drainage procedures. Gut, 5, 188-191.

McKelvey, S. T. D. (1970). Gastric incontinence and post-vagotomy diarrhoea. Brit. J. Surg., 57, 741-747.

McKelvey, S. T. D., Toner, D., Connell, A. M., and Kennedy, T. L. (1973). Coeliac and hepatic nerve function following selective vagotomy. Brit. J. Surg., 60, 219-221.

Mann, H., and Whitney, D. (1947). On a test of whether one of two random variables is stoichastically larger than the other. Ann. Math. Statist., 18, 50-60.

Novis, B. H., Bank, S., and Marks, I. N. (1971). The cephalic phase of pancreatic secretion in man. Scand. J. Gastroent., 6, 417-422.

Payne, R. A., Wighton, R., and Bluhm, M. (1970). Evaluation of drainage procedures combined with vagotomy. Proc. roy. Soc. Med., 63, 941-943.

Pfeffer, R. B., Stephenson, H. E., Jr., and Hinton, J. W. (1952). The effect of thoracolumbar sympathectomy and vagus resection on pancreatic function in man. Ann. Surg., 136, 585-594.

Sarles, H., Dani, R., Prezelin, G., Souville, C., and Figarella, C. (1968) Cephalic phase of pancreatic secretion in man. Gut, 9, 214-221.

Shiina, E., and Griffith, C. A. (1969). Selective and total vagotomy without drainage: a comparative study of gastric secretion and motility in dogs. Ann. Surg., 169, 326-333.

Smith, R. B., Edwards, J. P., and Johnston, D. (1973). Does the vagal nerve supply to the pancreas matter in man? (Abstr.) Brit. J. Surg., 60, 318.

Varley, H. (1967). Practical Clinical Biochemistry, 4th ed. Heinemann, London.

Walker, B. E., Kelleher, J. Davies, T. Smith, C. L., and Losowsky, M. (1973). Influence of dietary fat on fecal fat. Gastroenterology, 64, 233-239.

Wastell, C., and Ellis, H. (1966). Faecal fat excretion and stool colour after vagotomy and pyloroplasty. Brit. med. J., 1, 1194-1197.

Wheldon, E. J., Venables, C. W., and Johnston, I. D. A. (1970). Late metabolic sequelae of vagotomy and gastroenterostomy. Lancet, $1,437-440$.

Wilbur. B. G., and Kelly, K. A. (1973). Effect of proximal gastric, complete gastric and truncal vagotomy on canine gastric electric activity, motility and emptying. Ann. Surg., 178, 295-303.

Wilcoxon, F. (1945). Individual comparisons by ranking methods. Biomet. Bull., 1, 80-82.

Wilkinson, A. R., and Johnston, D. (1973). Effect of truncal, selective and highly selective vagotomy on gastric emptying and intestinal transit of a food-barium meal in man. Ann. Surg., 178, 190-193.

Wilkinson, R. (1971). Polyethylene glycol 4000 as a continuously administered non-absorbable faecal marker for metabolic balance studies in human subjects. Gut, 12, 654-660.

Williams, E. J., and Irvine, W. T. (1966). Functional and metabolic effects of total and selective vagotomy. Lancet, 1, 1053-1057.

Wollaeger, E. E., Comfort, M. W., and Osterberg, A. E. (1947). Total solids, fat and nitrogen in the feces: III. A study of normal persons taking a test diet containing a moderate amount of fat; comparison of results obtained with normal persons taking a test diet containing a large amount of fat. Gastroenterology, 9, 272-283. 